\title{
MODELOS FOTOQUÍMICOS SIMPLES COMO FERRAMENTA PARA O GERENCIAMENTO DA QUALIDADE DO AR
}

Cleyton M. da Silva ${ }^{\mathrm{a}, \mathrm{b}, \mathrm{c}}$, Bruno Siciliano ${ }^{\mathrm{a}}$, Nicole J. de Carvalho ${ }^{\mathrm{a}}$, Sergio M. Corrêa ${ }^{\mathrm{b}}$ e Graciela Arbilla ${ }^{\mathrm{a}, *, \bullet}$

anstituto de Química, Universidade Federal do Rio de Janeiro, 21941-909 Rio de Janeiro - RJ, Brasil

${ }^{b}$ Faculdade de Tecnologia, Universidade do Estado do Rio de Janeiro, 27537-000 Resende - RJ, Brasil

'Universidade Veiga de Almeida, Campus de Maracanã, 20271-020 Rio de Janeiro - RJ, Brasil

Recebido em 17/09/2018; aceito em 17/12/2018; publicado na web em 23/01/2019

\begin{abstract}
SIMPLE PHOTOCHEMICAL MODEL AS A TOOL FOR AIR QUALITY CONTROL. Atmospheric processes in an urban scenario are very complex and depend on meteorological parameters, emission, transport and deposition processes and the chemical mechanism. Simple air quality models can be used to understand the main aspects of ozone formation and provide information to adopt pollution control strategies. In this work the detailed simulation of ozone concentrations using the air quality model OZIPR (Ozone Isopleth Package for Research) coupled with the SAPRC (Statewide Air Pollution Research Center) chemical model is presented. First, the methods to determine volatile organic compounds (VOCs) are described as well as the statistical treatment of experimental data: Meteorological parameters (temperature, humidity, pressure, wind speed and direction), concentrations of nitrogen oxides $\left(\mathrm{NO}_{\mathrm{x}}=\mathrm{NO}_{2}+\mathrm{NO}\right)$, carbon monoxide $(\mathrm{CO})$ and ozone $\left(\mathrm{O}_{3}\right)$, which are needed to characterize the problem. Then, the construction and adjust of the model (base case) is detailed using, as an example, data for a typical urban area in the city of Rio de Janeiro. Finally, the limitations and the potential of the model are discussed. Clearly the quality of experimental data, mainly $\mathrm{NO}_{\mathrm{x}}$ and COVs concentrations and the COVs speciation, are a key information to obtain a correct estimation of $\mathrm{O}_{3}$ levels.
\end{abstract}

Keywords: air quality model; photochemical mechanism; criteria pollutants; volatile organic compounds; tropospheric ozone.

\section{INTRODUÇÃO}

Os processos que acontecem na atmosfera são complexos, não lineares e envolvem reações químicas, fenômenos meteorológicos, emissão, transporte e deposição de poluentes. Em laboratório, as câmaras de reação permitem o estudo de reações individuais e de misturas de ar em diferentes condições de pressão, temperatura, umidade e radiação, tanto em condições indoor (utilizando lâmpadas) como outdoor (utilizando radiação solar). Existem câmaras de reação construídas com diferentes materiais (vidro, quartzo, PTFEpolitetrafluoroetileno), em tamanhos desde poucos metros cúbicos até câmaras de 200 a $300 \mathrm{~m}^{3}$, equipadas com diversos instrumentos que permitem identificar e quantificar os produtos de reação na fase gasosa assim como os aerossóis formados. ${ }^{1}$ Utilizando esse tipo de experimentos foi possível validar mecanismos de reação em diferentes condições. Contudo, geralmente não é possível simular no laboratório condições ambientais, envolvendo todos os processos e a variabilidade de situações que podem ser encontradas, em relação aos processos de emissão, transporte, deposição e parâmetros meteorológicos. ${ }^{2}$

Para melhorar o conhecimento dos processos na atmosfera e, especialmente, para fornecer informações que possam auxiliar na tomada de decisões sobre estratégias de controle ambiental, foram desenvolvidos modelos de qualidade do ar. $^{3}$ Esses modelos permitem estimar as relações entre as emissões de poluentes e os processos físicos de transporte e deposição com as concentrações dos poluentes na atmosfera. ${ }^{2}$ Alguns modelos têm como objetivo descrever o transporte dos poluentes primários, enquanto outros, que incluem mecanismos detalhados dos processos químicos, permitem calcular as concentrações de ozônio e outros poluentes secundários em diferentes condições. Recentemente, Guarieiro et al. fizeram uma revisão dos principais modelos fotoquímicos disponíveis e suas aplicações. ${ }^{4}$

*e-mail: gracielaiq@gmail.com
Brevemente, existem duas abordagens para o problema de descrever a qualidade do ar e as concentrações dos poluentes: modelos empíricos (estatísticos) e modelos matemáticos. ${ }^{5}$ Os primeiros são apropriados para descrever cenários específicos e são parametrizados a partir de dados experimentais disponíveis para serem usados em caráter preditivo. Os modelos matemáticos têm diferentes graus de complexidade, desde modelos simples "em caixa" até modelos eulerianos 3D, que permitem a simulação de processos em escala urbana e regional. Este último tipo de modelos requer o conhecimento dos dados de entrada (meteorológicos, emissões e deposição) com uma resolução vertical de 50 a $1000 \mathrm{~m}$ e uma resolução horizontal de 1 a $10 \mathrm{~km} .^{2}$ Esta é provavelmente a maior dificuldade para o uso de modelos nas cidades brasileiras, onde, em geral, não se dispõe de dados com essa resolução.

Os modelos simples "em caixa”, como o OZIPR (Ozone Isopleth Package for Research), permitem apenas simular uma região homogênea (ou que possa ser aproximada como tal). ${ }^{2}$ Mesmo assim, em combinação com um modelo químico apropriado, fornecem informações importantes sobre a contribuição dos poluentes primários na formação dos poluentes secundários. Utilizado de forma criteriosa, esse tipo de modelo permite construir um caso base ou caso representativo de um determinado cenário, a partir de dados experimentais, e posteriormente inferir as mudanças que podem ser esperadas em outras condições do mesmo cenário. ${ }^{6}$

Esses modelos podem ser utilizados em combinação com diferentes mecanismos. Devido à complexidade dos processos químicos que envolvem os poluentes primários, principalmente os compostos orgânicos voláteis $(\mathrm{COV} s)$ e os óxidos de nitrogênio $\mathrm{NO}_{\mathrm{x}}$ (onde $\mathrm{NO}_{\mathrm{x}}=$ $\mathrm{NO}+\mathrm{NO}_{2}$ ), esses mecanismos envolvem uma série de aproximações, parametrizações e condensações. Os dois modelos mais utilizados são o SAPRC (Statewide Air Pollution Research Center), ${ }^{7}$ desenvolvido por Carter em 1990 e o CB (Carbon Bond), desenvolvido por Gery et $a l .{ }^{8}$ Ambos os mecanismos têm sido atualizados ao longo dos anos e validados com experimentos em câmaras de reação e, 
quando comparados, apresentam desempenho similar.9-11 O SAPRC foi desenvolvido especificamente para estudos de reatividade e é geralmente utilizado em trabalhos que têm esse propósito.

O objetivo deste trabalho é demonstrar como um modelo simples de qualidade do ar, tal como o modelo "em caixa" OZIPR e o mecanismo SAPRC, ambos de domínio público, podem ser utilizados para obter informações valiosas sobre a formação de ozônio em um ambiente urbano, desde que sejam fornecidos dados suficientes e tratados de uma forma criteriosa. O modelo foi aplicado a um estudo de caso, uma área urbana, representativa da cidade do Rio de Janeiro, mostrando quais os dados experimentais que devem ser obtidos e ilustrando o tratamento e interpretação dos dados.

\section{METODOLOGIA}

\section{Local de estudo}

A Região Metropolitana do Rio de Janeiro (RMRJ) está localizada na região sudeste do Brasil e é a segunda região metropolitana mais populosa do país. É formada pela cidade de Rio de Janeiro e outros 20 municípios. A cidade do Rio de Janeiro é a segunda maior cidade do Brasil, com uma população de aproximadamente 6,5 milhões de habitantes. ${ }^{12}$ De acordo com a classificação climática de Köppen, seu clima é atlântico tropical (Aw), quente e úmido, com temperaturas médias de $23{ }^{\circ} \mathrm{C}$ e $27{ }^{\circ} \mathrm{C}$, no inverno e verão, respectivamente. ${ }^{13} \mathrm{E}$ caracterizado por uma estação seca (de abril a setembro), na qual a precipitação média mensal é menor que $60 \mathrm{~mm}$ em pelo menos um dos meses. A precipitação média anual é de $1278 \mathrm{~mm}$ e a umidade relativa média varia entre 70 e $80 \% .{ }^{14}$

O estudo foi realizado na Praça Saens Peña (22,9248 S; 43,2331 O), localizada no bairro da Tijuca, na zona norte da cidade, como mostrado na Figura 1S. O bairro tem uma superfície de $1.006,56 \mathrm{~km}^{2}$ e uma população de 165.000 habitantes. ${ }^{13}$ Aproximadamente $30 \%$ da sua superfície é ocupada pela cobertura vegetal da Mata Atlântica ou por áreas de reflorestamento. A região é cercada por montanhas, que proporcionam uma estagnação do ar e impedem a chegada da brisa marinha. Os ventos mais frequentes são provenientes do sul e sudoeste. ${ }^{13,14} \mathrm{~A}$ área de estudo se encontra a menos de $1 \mathrm{~km}$ do Morro do Sumaré, com $700 \mathrm{~m}$ de altitude e vegetação da Mata Atlântica e a uma distância de cerca de $10 \mathrm{~km}$ de uma das entradas oficiais da Floresta da Tijuca. Esta última trata-se de um Parque Nacional e, com 39,53 $\mathrm{km}^{2}$, é considerada a maior floresta secundária urbana do mundo. ${ }^{15}$

Na Praça está localizada uma estação automática de monitoramento da qualidade do ar, operada pela Secretaria Municipal de Meio Ambiente (SMAC), uma estação de metrô, uma cabine da Policia Militar e a população realiza diversas atividades de lazer. A região tem um grande número de estabelecimentos comerciais e de serviços e intenso fluxo de veículos, principalmente veículos leves, particulares e taxis. Dependendo do horário do dia, o fluxo de tráfego de ônibus representa de 7 a $20 \%$ da frota total circulante na região. ${ }^{16}$ Ainda que a atividade econômica desta região seja bem ativa, não possui estabelecimentos industriais ou outras fontes de emissão fixas importantes, sendo as veiculares a única fonte antropogênica significativa. ${ }^{13,16}$

\section{Coleta dos dados experimentais}

Os COVs não oxigenados (hidrocarbonetos) foram coletados e analisados segundo o Método TO-15, desenvolvido pela Agência de Meio Ambiente dos Estados Unidos (U.S. EPA), ${ }^{17}$ previamente implementado, validado e descrito detalhadamente por Silva et al. ${ }^{18} \mathrm{em}$ um artigo publicado na revista Química Nova. O método estabelece os procedimentos gerais para a coleta de COVs usando canisters, botijões de aço inox eletropolidos internamente, e sua determinação utilizando a técnica de cromatografia gasosa acoplada à espectrometria de massas e termodessorção para injeção das amostras (CG-EMDT). Nas condições de análise utilizadas só foi possível determinar compostos não oxigenados no intervalo $\mathrm{C}_{4}-\mathrm{C}_{12}$. Para a determinação de compostos mais leves, seria necessário utilizar temperaturas menores no forno da coluna cromatográfica. Compostos oxigenados ou polares não foram determinados usando esse método porque são retidos no loop de peneira molecular.

Os compostos carbonílicos foram determinados utilizando o Método TO-11A, desenvolvido pela U.S. EPA. ${ }^{19}$ Neste método o ar é passado através de um cartucho com um material adsorvente impregnado com um reagente derivatizante que reage com os compostos carbonílicos. Neste trabalho foram utilizados cartuchos Sep-Pak ${ }^{\circledR}$ DNPH-Silica (360 mg) da Waters. Após a coleta, as hidrazonas formam extraídas com acetonitrila. A análise dos compostos foi realizada por cromatografia líquida de alta eficiência, com um detector de arranjo de diodos - DAD.

Como o objetivo era determinar as emissões primárias, as coletas foram realizadas no período de 8:00 às 9:00 h, horário em que o tráfego veicular é mais intenso e a radiação solar menor, minimizando a decomposição fotoquímica e as reações de fotooxidação dos compostos de interesse. A implementação e as condições experimentais dos métodos utilizados para a determinação dos hidrocarbonetos e dos compostos carbonílicos foram descritas detalhadamente em trabalhos anteriores. ${ }^{18,20}$

Os parâmetros meteorológicos (temperatura, umidade, radiação solar, precipitação, direção e velocidade do vento) e a concentrações dos poluentes legislados $\left(\mathrm{CO}, \mathrm{NO}_{2}, \mathrm{e} \mathrm{O}_{3}\right)$ foram fornecidos pela estação de monitoramento da qualidade do ar da SMAC. ${ }^{21}$ Os Índices de Qualidade do Ar (IQA), ${ }^{22-24}$ calculados pela SMAC, foram obtidos na homepage da SMAC. ${ }^{21}$ É importante mencionar que para realizar um estudo de simulação devem ser fornecidos dados, no mínimo, de médias horárias de temperatura, umidade e concentrações de $\mathrm{CO}, \mathrm{NO}$, $\mathrm{NO}_{2}$ e $\mathrm{O}_{3}$ para serem utilizados em combinação com as concentrações e especiação de COVs.

Os dados experimentais (parâmetros meteorológicos e concentrações) fornecidos pela estação de monitoramento e os dados de concentração foram tratados usando estatística descritiva para o cálculo das medianas. Os dados de concentração dos compostos orgânicos determinados neste trabalho foram tratados estatisticamente para o cálculo das medianas, máximos, mínimos, valores médios e desvio padrão. Mesmo não sendo estritamente necessário para a aplicação do modelo, todos os dados foram, também, apresentados na forma de boxplots e construídas as rosas dos ventos usando um código do pacote Openair na Linguagem R, de modo a melhorar o entendimento da qualidade dos dados disponíveis. ${ }^{25,26} \mathrm{O}$ tratamento de dados foi realizado usando planilhas de Excel e scripts na Linguagem R. ${ }^{25}$

\section{Modelo OZIPR}

O modelo de trajetórias OZIPR foi desenvolvido por solicitação da U.S. EPA para auxiliar na previsão de cenários de poluição urbana. ${ }^{27,28}$ Em linhas gerais, o OZIPR apresenta-se como um modelo relativamente simples, unidimensional, conhecido como modelo "em caixa" ou de trajetórias, que requer dados de concentrações iniciais, emissões de poluentes primários e parâmetros meteorológicos, com resolução temporal, sem a necessidade de uma descrição espacial destes parâmetros. Permite, ainda, o uso de diversos modelos químicos, inclusive aqueles com grau de complexidade e detalhamento elevado. ${ }^{27}$

O OZIPR possibilita a realização de múltiplas simulações para diversas condições de COVs e óxidos de nitrogênio $\left(\mathrm{NO}_{\mathrm{x}}\right)$, fornecendo um gráfico de isopletas para diferentes poluentes secundários em 
função destes dois precursores, sendo uma ferramenta muito útil na previsão de cenários e elaboração de estratégias de controle ambiental.

Pode-se entender o modelo como uma coluna de ar que na base engloba toda a região de estudo e que se projeta para cima até a camada de mistura da atmosfera, como se fosse uma caixa com uma tampa móvel, que é função da altura da camada de mistura ao longo do dia. Toda a caixa é considerada perfeitamente homogênea e move-se de acordo com a trajetória do vento, mas de modo a não se expandir horizontalmente. As emissões provenientes da base da coluna são computadas, assim como as deposições secas e úmidas podem ser implementadas. Desta forma, o OZIPR possibilita a simulação simplificada dos processos químicos e físicos que acontecem na troposfera urbana e a análise da influência dos parâmetros de entrada, especialmente da especiação dos COVs. ${ }^{2}$

Cabe ressaltar que esse modelo de trajetórias fornece bons resultados para localidades onde se pode considerar a atmosfera homogênea em toda a sua extensão. ${ }^{29}$ Para localidades onde as emissões não são bem distribuídas ou com uma topografia muito heterogênea é mais recomendado a utilização de modelos tridimensionais. Contudo, esse tipo de modelo requer uma quantidade de dados de entrada muito maior, e em uma resolução espacial tipicamente de 4 x $4 \mathrm{~km}$. Na indisponibilidade de dados com essa resolução, um modelo adimensional fornece resultados úteis, especialmente para o cálculo de reatividade ou para análises comparativas de dois cenários. ${ }^{30}$

Basicamente, os dados de entrada utilizados no OZIPR para uma simulação são: especiação dos COVs, ou seja, as concentrações individuais das diferentes espécies na mistura de $\mathrm{COV}$; ; concentrações iniciais totais de $\mathrm{NO}, \mathrm{NO}_{2}, \mathrm{COV}$ s totais e $\mathrm{CO}$; dados meteorológicos horários de temperatura, pressão, umidade e altura da camada de mistura; emissões primárias de $\mathrm{COV}$ s totais, $\mathrm{NO}_{\mathrm{x}}$ e $\mathrm{CO}$; localização geográfica e data (para o cálculo do fluxo solar actínico); coeficientes de deposição seca e úmida e modelo químico. Os dados de saída são as concentrações médias horárias das espécies químicas que se desejar e as isopletas dos poluentes secundários para intervalos de valores estabelecidos de $\mathrm{COVs}$ e $\mathrm{NO}_{\mathrm{x}} \cdot{ }^{27}$

Neste trabalho, os dados meteorológicos e as concentrações iniciais de $\mathrm{CO}$ e $\mathrm{NO}_{x}$ foram fornecidos pela estação de monitoramento da $\mathrm{SMAC}$, assim como as concentrações horárias de $\mathrm{CO}, \mathrm{NO}_{\mathrm{x}}$ e $\mathrm{O}_{3}$ usadas no ajuste do modelo. As concentrações individuais dos compostos orgânicos foram determinadas usando os Métodos TO-15 e TO-11A, já descritos. As emissões de poluentes foram usadas como parâmetros de ajuste, como será descrito no item Resultados. A altura da camada de mistura foi determinada usando dados experimentais obtidos no Aeroporto Galeão e o método de ajuste apresentado nos Resultados.

O modelo OZIPR foi utilizado em conjunto com o mecanismo fotoquímico SAPRC, descrito no item seguinte.

\section{Mecanismo fotoquímico}

Os COVs reagem na atmosfera com radicais hidroxila $(\cdot \mathrm{OH})$, ozônio e radicais nitrato $\left(\mathrm{NO}_{3}\right)$, formando radicais. Durante o dia, a principal via de reação é com os radicais $\cdot \mathrm{OH}$. No entanto, para os compostos com dupla ligação, a via de ozonólise também acontece. Através dessas reações são formados radicais alquila e peroxialquila, que na presença de $\mathrm{O}_{2}$ e $\mathrm{NO}$ levam à transformação de $\mathrm{NO}$ em $\mathrm{NO}_{2}$. Esse último se decompõe fotoquimicamente, formando átomos de oxigênio que, na presença de $\mathrm{O}_{2}$, levam à formação de ozônio, principal poluente secundário em ambientes urbanos. O mecanismo completo é muito complexo e envolve centenas de reações químicas. ${ }^{2,31,32}$

O modelo químico é uma parte fundamental dos modelos de qualidade do ar, já que se ele for incompleto ou incorreto irá fornecer concentrações erradas dos poluentes secundários formados a partir dos poluentes primários. A maioria dos modelos de qualidade do ar tem como principal objetivo o cálculo das concentrações de ozônio. Paralelamente, os modelos permitem avaliar o potencial de formação de ozônio dos compostos orgânicos voláteis e construir escalas de reatividade para esses compostos, os COVs.

Diversos mecanismos têm sido propostos na literatura. ${ }^{4}$ Por sua versatilidade, documentação detalhada, disponibilidade pública e ampla aceitação, neste trabalho foi utilizado o modelo químico SAPRC, que foi desenvolvido para a simulação da qualidade do ar urbano. O SAPRC-90 foi desenvolvido e proposto por Carter em 1990 na Universidade de Riverside e, desde o seu início, teve diversas atualizações (como SAPRC-07 e SAPRC-11). ${ }^{33,34}$

O modelo SAPRC-90 original foi amplamente testado contra 550 experimentos controlados em câmaras de reação, obtendo excelentes resultados para os mais diferentes conjuntos experimentais, o que não seria o suficiente para comprovar a sua total eficiência para um determinado cenário. Posteriormente foi atualizado dando lugar à versão SAPRC-99, que foi avaliada comparando com os resultados de aproximadamente 1700 experimentos, também realizados em câmaras de reação na Universidade da Califórnia em Riverside, que incluíram 80 tipos de COVs. Finalmente foi disponibilizada a versão SAPRC-07, avaliada com 2400 experimentos em 11 câmaras de reação diferentes e com 120 tipos de COVs. ${ }^{34,35}$ É provavelmente o mecanismo mais utilizado e tem sido implementado para diferentes modelos de qualidade do ar, desde modelos em caixa, como o OZIPR (utilizado neste trabalho), até modelos 3D.

Uma das maiores vantagens na utilização desse modelo é a fácil modificação e posterior adequação para o cenário proposto: os arquivos encontram-se em modo texto e, com isso, as diversas variáveis são reprogramáveis. Além disso, o mecanismo está bem documentado e é possível obter atualizações periódicas (a última de 2013) no site do modelo. ${ }^{34}$

O mecanismo SAPRC tem uma estrutura modular e inclui as reações das espécies inorgânicas, orgânicas e dos intermediários radicais que levam aos produtos finais. Em seu mecanismo base, alguns compostos orgânicos são representados em forma individual ou explícita, e outros em forma de grupos (lumped model). Os compostos explicitados de forma individual são os que têm maior importância química, ou ainda que não podem ser agrupados, porque sua reatividade é diferente da dos demais compostos.

Neste trabalho foi utilizada uma versão atualizada pelo nosso grupo de pesquisa, ${ }^{30,36}$ que considera 214 reações e 83 espécies. Alguns compostos foram considerados em forma explícita (formaldeído, acetaldeído, metano, eteno, 1,3-butadieno, isopreno, etanol) e outros em forma agrupada (cinco agrupamentos de alcanos, dois grupos de alcenos e dois de aromáticos) como será detalhado nos Resultados.

\section{RESULTADOS E DISCUSSÃO}

\section{Concentrações dos compostos orgânicos voláteis}

Foram realizadas duas campanhas de coleta ( 8 amostras em cada campanha): uma no mês de março de 2015 (período úmido) e outra entre 15 de maio e 15 de junho de 2015 (período seco). Segundo informações do Sistema Alerta Rio, ${ }^{37}$ da Prefeitura da Cidade do Rio de Janeiro, os dados mensais pluviométricos acumulados para a Estação Tijuca (Muda), localizada na Escola Municipal Soares Pereira (Avenida Maracanã, 1450), foram de 133 e $13 \mathrm{~mm}$, para os períodos de amostragem: mês de março e 15 de maio-15 de junho, respectivamente.

Foram determinados 52 compostos na faixa $\mathrm{C}_{4}-\mathrm{C}_{12}$, sendo que o $\mathrm{m}$ e p-xilenos coeluem nas condições de análise. O 1-hexeno, isooctano, 2,3,4-trimetilpentano, 1,3-dietilbenzeno e 1,4-dietilbenzeno se encontraram abaixo do limite de quantificação $\left(1,2 \mu \mathrm{g} \mathrm{m}^{-3}\right) \mathrm{em}$ 
todas as amostras. A concentração total (valor médio) foi de 163 e $336 \mathrm{~g} \mathrm{~m} \mathrm{~m}^{-3}$, para a primeira e segunda campanha, respectivamente. Na Figura 1 são apresentadas as concentrações dos 28 COVs mais abundantes que estavam presentes em ao menos $80 \%$ das amostras analisadas nos dois períodos de coleta: campanha 01 no período úmido e campanha 02 no período seco. As figuras foram construídas na forma de boxplot, o que permite a visualização das medianas, dos valores mais prováveis (através da indicação do primeiro e terceiro quartis, Q1 e Q3, respectivamente), assim como dos mínimos (dentro de 1,5 do menor quartil), máximos (dentro de 1,5 do maior quartil), extremos e outliers. ${ }^{38}$ Neste trabalho, o tamanho da caixa é o comprimento inter-quartil (IQR = Q3-Q1) e a mediana é indicada com uma linha preta dentro da caixa. Os whiskers se estendem entre o mínimo e o máximo e os outliers são indicados com círculos.

Os compostos mais leves (principalmente etano, eteno, propano e propeno) são importantes, seja pela suas abundâncias ou pelas suas reatividades. Porém, eles não podem ser determinados nas condições de análise disponíveis neste trabalho. Como o objetivo deste trabalho é apresentar o procedimento para realizar uma simulação, o fato de não ter sido possível determinar esses compostos não compromete os resultados e conclusões.

As concentrações (valores médios) de formaldeído e acetaldeído foram de 2,3 e 3,3 $\mathrm{g} \mathrm{m} \mathrm{m}^{-3}$, respectivamente. Por motivos de

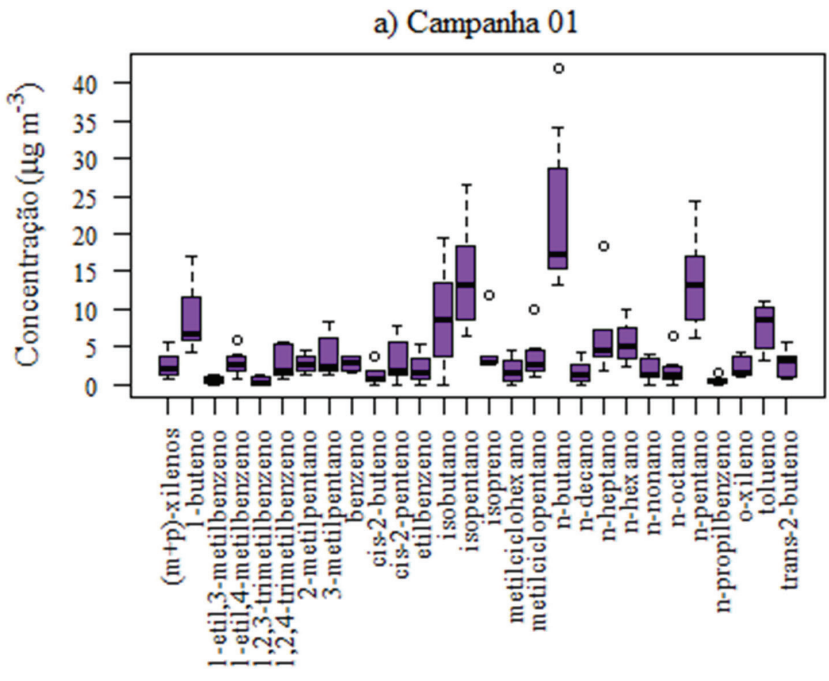

b) Campanha 02

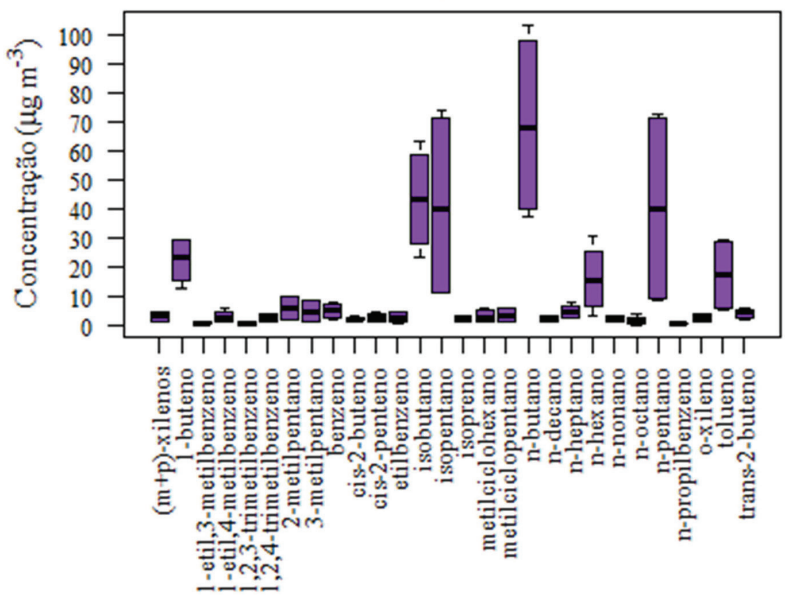

Figura 1. Boxplot com a concentrações determinadas para os COVs, usando o Método TO-15; a) campanha 01: março 2015 (período úmido); b) campanha 02: 15 de maio a 15 de junho (período seco) disponibilidade de equipamento foi realizada apenas a campanha 01 e, assim, na simulação da campanha 02 foi usado esse valor como uma aproximação.

Neste trabalho as concentrações dos compostos orgânicos voláteis serão usadas apenas como dados de entrada do modelo químico e, por esse motivo, não será realizada uma discussão das mesmas e uma comparação com outros dados da literatura. Pelo mesmo motivo foi coletado um número reduzido de amostras, apenas com o intuito de mostrar que tipo de resultados experimentais são necessários para implementar um modelo fotoquímico de qualidade do ar. Porém, é importante mencionar que os resultados são consistentes com os obtidos em outros estudos realizados recentemente na cidade de Rio de Janeiro usando os mesmos métodos de coleta e análise. ${ }^{6,16,36,39}$

Para serem utilizados na simulação, os dados de concentração foram convertidos a unidades de ppmC e os COVs foram agrupados usando um critério combinado: em primeiro lugar as espécies foram agrupadas por funções químicas (alcanos, alcenos etc.) e, posteriormente, foi realizado um novo agrupamento (i.e., alcanos 1 , alcanos 2 etc.) com base na sua reatividade com respeito ao radical $\cdot \mathrm{OH}$. Considerando os valores dos coeficientes de velocidade para as reações dos compostos orgânicos com radical hidroxila, geralmente são usados cinco grupos de alcanos, dois de alcenos e dois de compostos aromáticos, como mostrado na Tabela 1S. Neste trabalho foram utilizados esses agrupamentos. ${ }^{33,34}$ Os outros compostos determinados experimentalmente (isopreno, formaldeído, acetaldeído) foram tratados em forma explícita.

\section{Dados da estação de monitoramento}

Os dados de concentração de $\mathrm{CO}, \mathrm{NO}_{2}$ e $\mathrm{O}_{3}$ fornecidos pela estação de monitoramento localizada na Praça Saens Peña, em intervalos de 10 minutos, foram organizados numa planilha de Excel para o cálculo dos valores horários médios, mediana, mínimo e máximo para os dois períodos estudados. Para a simulação das concentrações de ozônio, usando o modelo de qualidade do ar, são necessárias apenas os valores das medianas (ou eventualmente os valores médios).

Porém, com o objetivo de conseguir uma melhor compreensão da variabilidade dos dados experimentais foram construídas figuras na forma de boxplots e apresentadas no Material Suplementar. Nas Figuras $2 \mathrm{~S}$ e $3 \mathrm{~S}$ são apresentados os resultados para as duas campanhas, para os poluentes legislados $\mathrm{CO}, \mathrm{O}_{3}$ e $\mathrm{NO}_{2}$. As concentrações de ozônio no período 15 de maio a 15 de junho foram menores que no mês de março, no qual houve, inclusive, algumas ultrapassagens ao padrão primário de qualidade do ar de $160 \mu \mathrm{g} \mathrm{m}^{-3}$, configurando um IQA com classificação Inadequada. ${ }^{21-24}$ Já no período seco foram observadas concentrações maiores de $\mathrm{NO}_{2}$ e $\mathrm{CO}$ em muitos horários, como é geralmente encontrado para poluentes primários. Da mesma forma, as concentrações totais de COVs determinadas nas duas campanhas são muito diferentes, com valores aproximadamente o dobro para a campanha 02. Essas observações justificam a elaboração de dois casos base ou modelos representativos, um para cada período e a análise detalhada da distribuição de compostos orgânicos, concentrações de $\mathrm{CO}$ e $\mathrm{NO}_{x}$ e valores dos parâmetros meteorológicos para os dois períodos, como será apresentado nos itens seguintes.

Finalmente, deve ser mencionado que para as simulações são necessárias informações das concentrações de $\mathrm{NO}$ e $\mathrm{NO}_{2}$, ou seja, do $\mathrm{NO}_{x}=\mathrm{NO}+\mathrm{NO}_{2}$. Porém, para discutir as ultrapassagens dos padrões de qualidade do ar, devem ser consideradas apenas as concentrações de $\mathrm{NO}_{2}$, já que o $\mathrm{NO}$ não é um poluente legislado. ${ }^{40}$

Os dados meteorológicos de temperatura e umidade foram tratados da mesma forma que os de concentrações dos poluentes legislados. Nas Figuras 4S e 5S são apresentados os resultados para as duas campanhas. As medianas da temperatura máxima para o mês 
de março e para o período 15 de maio a 15 de junho de 2015 foram, de 31,77 e $28,39{ }^{\circ} \mathrm{C}$. Mesmo não sendo estritamente comparáveis, pode ser mencionado que esses valores são maiores que as normais climatológicas (1961-1990) para as temperaturas máximas na cidade de Rio de Janeiro, para os meses de março $\left(29,4{ }^{\circ} \mathrm{C}\right)$, maio $\left(26,4{ }^{\circ} \mathrm{C}\right)$ e junho $\left(25.2{ }^{\circ} \mathrm{C}\right) .{ }^{41}$ Contudo, esses valores diferem em $<5 \%$ dos valores esperados conforme as normais climatológicas (temperaturas máximas) recentemente publicadas para o período $1981-2010: 31{ }^{\circ} \mathrm{C}$ (março), $27,80{ }^{\circ} \mathrm{C}$ (maio) e $26,70{ }^{\circ} \mathrm{C}$ (junho)..$^{41}$

Para a umidade, as medianas variaram entre 45,32 e $80,83 \%$ e 46,02 e 75,23\% para o mês de março e para o período 15 de maio a 15 de junho de 2015 , respectivamente.

Os dados de velocidade e direção do vento não entram como parâmetros do modelo em forma direta. Porém, é importante a análise prévia desses valores para auxiliar na interpretação dos dados experimentais e calculados de concentrações de poluentes primários e secundários, já que a velocidade e direção do vento influencia diretamente o transporte de poluentes. As rosas dos ventos foram construídas ${ }^{25,26}$ para três períodos horários, correspondentes à manhã, tarde e noite. Os resultados são apresentados nas Figuras 6S e 7S.

Observa-se que o padrão de ventos mais frequentes foi diferente nas campanhas 01 e 02 e nos diferentes horários do dia. No mês de março, durante a tarde e à noite, predominam ventos do sul e sudoeste, sendo mais fracos durante o período noturno. Durante a manhã os ventos provêm do sudoeste e nordeste. Já no período 15 de maio a 15 de junho, durante a manha predominam ventos fracos do nordeste e durante a tarde e à noite ventos do sul e sudoeste. De qualquer forma, os ventos predominantes são fracos (até $1 \mathrm{~m} \mathrm{~s}^{-1}$ ) e a velocidade máxima é de $3,3 \mathrm{~m} \mathrm{~s}^{-1}$, característica de uma área da cidade pouco ventilada e que não recebe brisa marinha.

Da mesma forma foram analisados os dados de radiação solar, mesmo que eles não sejam incorporados diretamente como entrada no modelo de qualidade do ar. Os resultados, na forma de boxplots, são mostrados na Figura 8S. Como esperado, no mês de março houve valores maiores (de até $1.000 \mathrm{~W} \mathrm{~m}^{-2}$ ), porém a mediana para ambos os períodos foi semelhante (em torno de $600 \mathrm{~W} \mathrm{~m}^{-2}$ ). Isto se deve ao fato de que, como informado no item 3.1, no mês de março o volume de chuvas foi muito maior $(133 \mathrm{~mm})$ que no período de 15 de maio a 15 de junho de $2015(13 \mathrm{~mm}) \cdot{ }^{37}$ A precipitação durante a campanha 01 se encontrou dentro do esperado, mas o período da campanha 02 foi anormalmente seco, já que as normais climatológicas para a cidade de Rio de Janeiro (1961-1990), nos meses de março, maio e junho são 135,$8 ; 69,8$ e 42,7 mm. ${ }^{41}$ Não se dispõe de dados mais recentes para essas normais climatológicas.

\section{Simulação das concentrações de ozônio}

Inicialmente foi construído um modelo, chamado neste trabalho de caso base 1, para a primeira campanha, realizada no mês de março de 2015. As simulações foram realizadas para o período diurno, desde as 6:30 até as 18:30 h. As concentrações iniciais usadas para a simulação do cenário base foram determinadas a partir dos dados experimentais (medianas) obtidos durante o mês de março de 2015: 0,370 ppmv e 0,028 ppmv para $\mathrm{CO}$ e $\mathrm{NO}_{x}$, respectivamente. A concentração inicial de COVs e a especiação dos mesmos foram determinadas conforme já descrito. Inicialmente as concentrações dos COVs foram convertidas para unidades de ppmC e os compostos foram agrupados conforme os critérios indicados na Tabela 1S. Os valores calculados para o caso base 1 são mostrados na Tabela 2S. A concentração inicial total de COVs (oxigenados e não oxigenados) em unidades de ppmC foi de 0,248.

A especiação dos COVs foi mantida constante durante toda a simulação. É provável que essa distribuição dos compostos mude durante o dia, seja por mudanças no perfil de emissões e/ou como consequência das reações químicas, porém, o programa OZIPR não permite mudar a especiação dos compostos durante a simulação. ${ }^{27}$

Os dados horários de temperatura e umidade foram obtidos, como já mencionado, pela estação de monitoramento, e utilizado os valores (medianas) para o período de 01 de março a 31 de março de 2015. A partir dos ângulos zenitais, nos diferentes horários, calculados utilizando a latitude (22.979 S) e longitude (43.232 O) da cidade de Rio de Janeiro, e a radiação solar do dia 15 de março, foram estimados os coeficientes de velocidade dos processos fotoquímicos. O cálculo é realizado pelo programa OZIPR a partir dos dados de latitude, longitude e data, utilizando uma sub-rotina específica.

A variação horária da altura da camada de mistura não está disponível para a cidade do Rio de Janeiro. Nessas condições, são adotados um dos seguintes procedimentos: a) são usados um valor experimental para o início do dia e valores típicos para o resto do dia, sendo usado esse parâmetro como parâmetro de ajuste junto com as emissões de $\mathrm{CO} ;{ }^{42}$ b) é feita uma estimativa da altura da camada de mistura a partir de dados de temperatura do ar, sem usar esses valores como parâmetros de ajuste do modelo. , $36,43^{-}$

Neste trabalho foi usada uma combinação de ambos procedimentos. Inicialmente os valores foram escolhidos usando o valor experimental para as 10:00 h obtidos para a estação de radiossondagem localizada no Aeroporto Internacional do Rio de Janeiro - Antônio Carlos Jobim - Rio Galeão, disponível na base de dados do Laboratório Master da IAG-USP, ${ }^{44}$ e os outros valores foram ajustados seguindo o perfil de temperatura do ar para esse dia, como apresentado na Figura 9S. Posteriormente foi realizado um pequeno ajuste junto com as emissões de CO.

Para os coeficientes de deposição dos gases foram usados os valores propostos na literatura, ${ }^{2}$ como sendo valores médios ou faixas de valores mais frequentes, já que não estão disponíveis dados para locais específicos.

Não existem dados detalhados de emissões para a cidade do Rio de Janeiro. Um procedimento bastante utilizado é ajustar as emissões para o CO (usando como base os dados experimentais de uma estação de monitoramento) já que o CO é uma espécie pouco reativa. Posteriormente é estabelecido um valor para a relação das emissões (i.e., $\mathrm{COV}$ s $/ \mathrm{NO}_{\mathrm{x}} / \mathrm{CO}$ ) e mantidos constantes estes valores durante a simulação já que essa relação depende fundamentalmente, em um ambiente urbano, das características da frota, qualidade dos combustíveis e trânsito veicular. ${ }^{42}$

$\mathrm{Na}$ literatura são apresentados diversos valores para a relação $\mathrm{COV} / \mathrm{NO}_{x} / \mathrm{CO}$ determinados a partir de diversas fontes: inventário de emissões veiculares; dados de concentração medidos em túneis; dados ambientais de concentração medidos na primeira hora da manhã em alguns locais. Cada um desses métodos fornece resultados diferentes e nenhum deles representará satisfatoriamente a relação para o local estudado. ${ }^{45-50}$

Existem evidencias de que essas relações variam muito ao longo do dia, bem como em finais de semana, uma vez que ocorrem diferenças significativas nas atividades antropogênicas, como por exemplo, o tráfego veicular (principal fonte de emissão de COVs e $\mathrm{NO}_{\mathrm{x}}$ em ambientes urbanos), que se apresenta distinto entre dias da semana e finais de semana, bem como ao longo de um mesmo dia. ${ }^{36}$

Neste trabalho optou-se por não usar relações fixas e ajustar as emissões de poluentes utilizando como guia aproximada os valores experimentais de concentração fornecidos pela estação de monitoramento em combinação com uma análise das condições de trânsito na região estudada e dos valores típicos para as relações $\mathrm{COV} / \mathrm{NO}_{x} / \mathrm{CO}$.

Inicialmente, as emissões de $\mathrm{CO}$ foram ajustadas para reproduzir os dados experimentais de concentração obtidos pela estação de monitoramento durante o mês de março. $\mathrm{O}$ ajuste das emissões de 
$\mathrm{CO}$ a partir dos valores experimentais de concentração é considerada uma aproximação razoável ao problema, isso porque esse poluente é quimicamente pouco reativo e, sendo assim, suas mudanças de concentração são devidas fundamentalmente aos processos de emissão, transporte e diluição. Note-se que nesta etapa foram usados como parâmetros de ajuste apenas a altura da camada de mistura e as massas de $\mathrm{CO}$ emitidas. No caso da altura da camada de mistura foi feito apenas um pequeno ajuste, já que os valores originais tinham sido determinados a partir do perfil de temperatura do ar. Os outros parâmetros meteorológicos e as concentrações iniciais foram valores experimentais. Posteriormente foram ajustadas as emissões de $\mathrm{NO}_{\mathrm{x}} \mathrm{e}$ comparadas com os valores experimentais, e finalmente as emissões dos COVs até lograr um ajuste razoável das concentrações de $\mathrm{O}_{3}$.

Ao realizar esses ajustes foi levada em consideração a variação da tipologia de emissões ao longo do dia no local estudado, no qual a principal fonte de emissão é o trânsito veicular. No entanto, ao longo do dia ocorre uma variação do tipo de frota veicular existente, na qual o número de veículos leves se torna significativo nos horários de tráfego veicular intenso. Dessa forma, é provável que a relação de emissões $\mathrm{COV} / \mathrm{NO}_{\mathrm{x}} / \mathrm{CO}$ mude ao longo do dia e seja diferente dos valores médios para a região Metropolitana do Rio de Janeiro e Brasil. Na Tabela 3S são apresentados os valores utilizados neste trabalho, calculados a partir dos ajustes realizados para a representação do caso base.

Na Figura 10S são apresentados os valores de concentrações experimentais (medianas para o mês de março) e calculados para o CO. Observa-se que as concentrações calculadas a partir das estimativas de emissões realizadas são apenas uma aproximação aos valores experimentais, mas levando-se em conta a grande dispersão dos resultados cedidos pela estação de monitoramento foi considerado que o ajuste do modelo era adequado para os propósitos deste trabalho, já que o caso base tem como objetivo apenas representar as condições típicas da região estudada e não um dia ou mês em particular. As barras de erro nessa figura e as seguintes correspondem ao erro estimado para os dados experimentais.

Como já explicado, após o ajuste das emissões de CO foi realizado o ajuste das emissões de $\mathrm{NO}_{\mathrm{x}}$ tendo como base os valores experimentais obtidos da estação da SMAC (Figura 11S). Posteriormente foi realizado o ajuste final das emissões de COVs, de forma que as concentrações calculadas fossem o mais próximas possível dos valores experimentais de $\mathrm{O}_{3}$. Na Figura 2 são comparadas as concentrações simuladas entre 06:30 e 18:30 h, para $\mathrm{O}_{3}$, num acordo razoável com as medianas dos dados experimentais do período de 01 a 31 de março de 2015. Nas simulações apresentadas foi utilizada uma radiação solar correspondente a $80 \%$ do valor total correspondente a um dia totalmente sem nuvens, valor considerado representativo das condições reais no local estudado. $\mathrm{O}$ valor máximo de ozônio foi obtido para às 13:37 h, sendo de 22,36 ppbv, e o valor experimental (mediana) de 22,64 ppbv.

Posteriormente foi construído um novo modelo, chamado neste trabalho de caso base 2, para a segunda campanha de monitoramento, realizada entre 15 de maio e 15 de junho de 2015 , com o objetivo de verificar a sensibilidade dos resultados a variações nos parâmetros de entrada. As concentrações iniciais usadas para a simulação do cenário base foram determinadas a partir dos dados médios experimentais obtidos na estação de monitoramento durante o período de 15 de maio a 15 de junho de 2015: CO 0,425 ppmv e $\mathrm{NO}_{\mathrm{x}}$ 0,033 ppmv. A concentração inicial total de COVs (oxigenados e não oxigenados), obtida como previamente, em unidades de ppmC foi de 0,577. A especiação para o caso base 2 (campanha 02) é apresentada na Tabela 4S.

Foi usada a radiação solar (80\%) do dia 30 de maio e realizado um novo ajuste das emissões, sendo obtidas as Figuras $12 \mathrm{~S}$ e 13S, nas quais são apresentados os valores de concentrações experimentais (medianas para o mês de maio) e calculados para o $\mathrm{CO}$ e $\mathrm{NO}_{x}$, respectivamente. A simulação para as concentrações de $\mathrm{O}_{3}$ é apresentada na Figura 3. O valor máximo de ozônio foi obtido para às 15:05 h, sendo de 21,07 ppbv, e o valor experimental (mediana) de 22,88 ppbv.

Apesar das semelhanças entre os perfis de ozônio mostrados nas Figuras 2 e 3 e dos máximos calculados diferirem em menos de $10 \%$, os casos base 1 e 2 foram ajustados de forma diferente (especialmente os parâmetros meteorológicos e as emissões). Como já observado, as concentrações de COVs totais na campanha 02 foram aproximadamente o dobro que na campanha 01 e as especiações foram, também, diferentes.

Por ser um modelo empírico, ajustado a partir de dados experimentais, as predições do mesmo dependem fortemente da qualidade dos dados. As maiores incertezas estão relacionadas à determinação experimental da especiação dos COVs, ao desconhecimento das concentrações de algumas espécies e à falta de dados sobre altura da camada de mistura e emissão de poluentes primários.

Considerando que o Método TO-15 preconiza como aceitável um erro de $25 \%$ na determinação dos $\mathrm{COVs},{ }^{18}$ foi realizada uma simulação, para o caso base 1 , considerando um valor total de COVs superestimado em $+25 \%$, bem como subestimado em $-25 \%$. Os novos valores calculados para as concentrações de $\mathrm{O}_{3}$ são demonstrados na Figura 4.

Considerando uma concentração total de COVs superestimada em $+25 \%$, a concentração máxima de $\mathrm{O}_{3}$ obtida foi de 26,02 ppbv às $13: 37 \mathrm{~h}$, sendo esta equivalente a 16,4\% maior que o valor máximo encontrado para o caso base. Já ao considerar uma concentração de

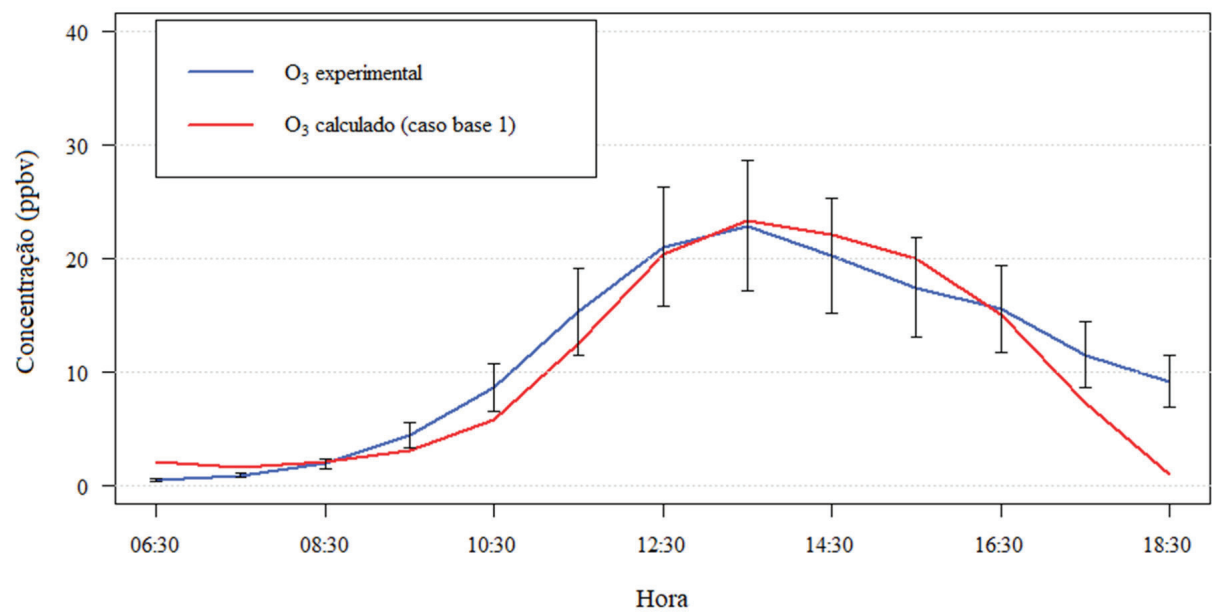

Figura 2. Valores de concentração simulados e experimentais para o $O_{3}$. Concentrações em unidades de ppbv (caso base 1) 


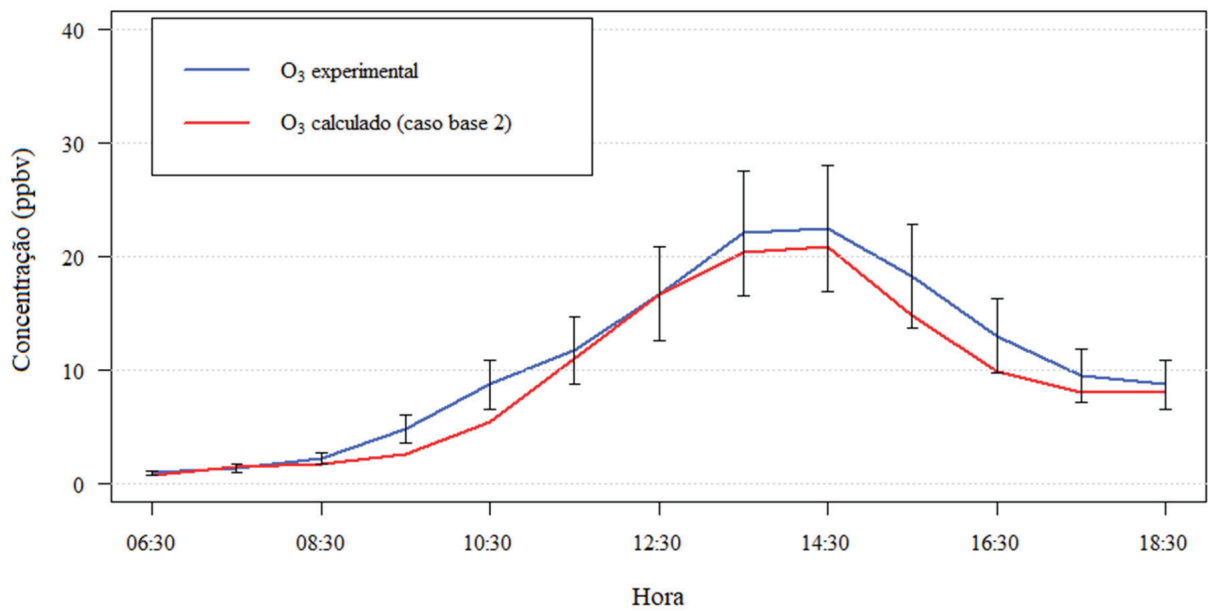

Figura 3. Valores de concentração simulados e experimentais para o $\mathrm{O}_{3}$. Concentrações em unidades de ppbv (caso base 2)

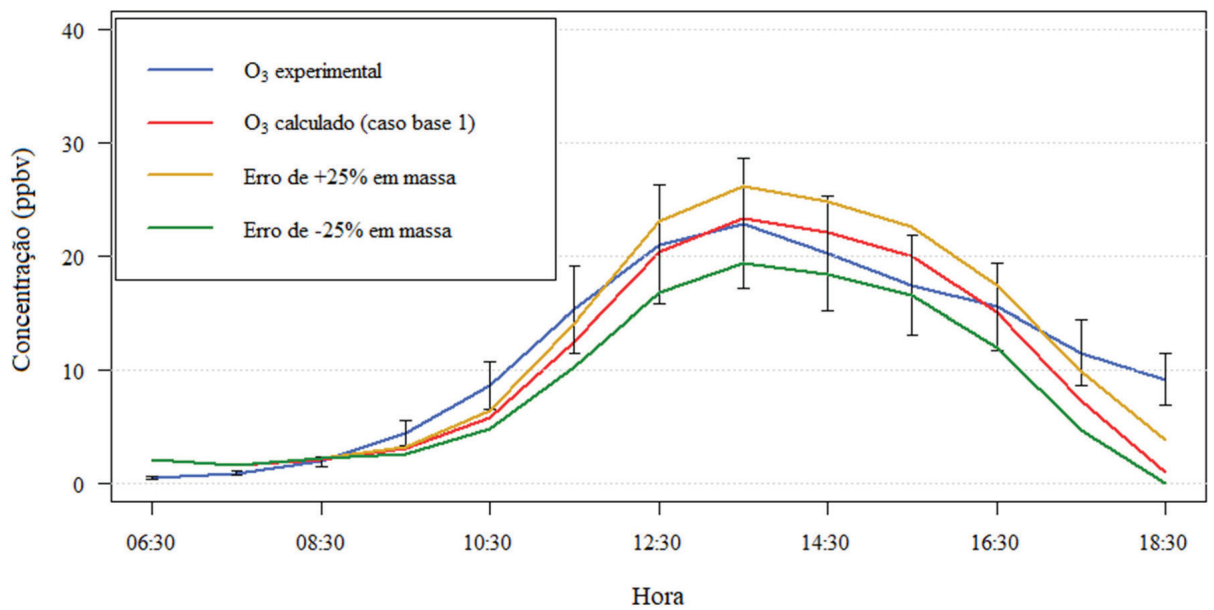

Figura 4. Valores de concentração simulados e experimentais para o $O_{3}$, considerando o caso base e erro de $+/-25 \%$ da massa total de COVs. Concentrações em unidades de ppbv

COVs subestimada em -25\%, obteve-se uma concentração máxima de $\mathrm{O}_{3}$ de 19,25 ppbv às 13:39 h, equivalendo a 13,9\% menor que o valor máximo encontrado para o caso base. Assim, aproximadamente, o erro na concentração calculada de ozônio, devido à incerteza na concentração dos COVs medidos experimentalmente, e de $\pm 15 \%$.

A importância dos compostos individuais para a formação de ozônio depende de sua reatividade e de sua concentração. Dessa forma, erros na determinação das concentrações irá afetar os resultados de forma diferente. Uma das formas mais usuais de discutir a contribuição das diferentes espécies é usando a escala de reatividade incremental (MIR) proposta por Carter. ${ }^{34}$ Brevemente, essa escala de reatividade está baseada em cálculos do impacto relativo à formação de ozônio, expressos como a massa adicional de ozônio formada, por unidade de massa do composto orgânico que está sendo considerado para determinado cenário (condições atmosféricas, localização, época do ano e composição da atmosfera) usando um determinado modelo fotoquímico. Resultados recentes obtidos por Alvin et al. para a Região Metropolitana de São Paulo mostram que, nesse cenário, onde o formaldeído e o acetaldeído representam aproximadamente 35\% dos COVs totais, a sua contribuição para a formação de ozônio é de $74 \% .{ }^{51}$ As concentrações dos compostos carbonílicos na cidade do Rio de Janeiro são aproximadamente 10 vezes menores e, assim, sua contribuição para a formação de ozônio é menor. Cálculos realizados para o caso base 1 , eliminando da mistura de COVs o formaldeído e acetaldeído, mostram que o máximo da concentração de ozônio é aproximadamente $30 \%$ menor. Esse resultado reforça a importância da determinação dos compostos carbonílicos na atmosfera urbana para obter resultados confiáveis na simulação e a importância de medidas de controle que levem à redução das concentrações destes compostos na atmosfera.

Também é importante mencionar que alguns compostos não foram determinados e, por esse motivo, não foram incluídos na simulação, principalmente os hidrocarbonetos na faixa $\mathrm{C}_{2}-\mathrm{C}_{3}$, que em outros trabalhos têm se mostrado importantes. ${ }^{52}$ Em particular, o etanol presente na atmosfera não foi determinado neste trabalho e, considerando estudos referentes às concentrações deste composto na atmosfera, realizou-se uma simulação de forma a estimar o erro pela não determinação do mesmo.

Alvim et al. determinaram as concentrações de etanol na estação CETESB IPEN/USP, nos anos de 2011 e 2012, obtendo valores de 22,4 a 47,4 ppbv (equivalendo a valores de 44,8 a 94,8 ppbC) que correspondem a aproximadamente $22,6 \%$ do total de COVs. ${ }^{53}$ Utilizando esses valores, Alvim et al. publicaram recentemente um estudo de reatividade e calcularam o potencial formador de ozônio do etanol entre - 0,03 e - 0,55 (dependendo da época do ano). ${ }^{51}$

Em outro estudo, Orlando ${ }^{43}$ utilizou as concentrações determinadas por Cólon et al. na Região Metropolitana de São Paulo, ${ }^{50}$ sendo esse valor de 412 ppbv (o equivalente a $824 \mathrm{ppbC}$ ), o que representava $66,64 \%$ do total de compostos orgânicos considerados no trabalho (1.236 ppmC). ${ }^{43}$ Cabe ressaltar que na época em que foi realizado o estudo de Orlando a proporção de carros que utilizavam etanol como combustível era maior que a observada atualmente e 
que a tecnologia automotiva tem evoluído, tornando o processo de combustão mais eficiente.

Desta forma, ainda sendo conservativo, foi considerado que um valor de $50 \%$ da mistura de COVs (em ppmC) utilizada neste trabalho fosse composta de etanol. Assim sendo, atribuiu-se valor igual a 0,248 ppmC (valores determinados de COVs) para o etanol, obtendo-se um valor total de $0,496 \mathrm{ppmC}$. Os valores calculados no caso base e valores experimentais de $\mathrm{O}_{3}$, comparados à simulação utilizando 50\% de etanol, estão demonstrados na Figura 5, obtendo-se um valor máximo de ozônio de 17,17 ppbv às 14:20 h, sendo um erro de - $23 \%$ referente ao valor obtido para o caso base. Considerando que todos os estudos publicados após 1990 mostraram concentrações de etanol muito menores que as reportadas por Orlando, ${ }^{43} \mathrm{o}$ erro devido à impossibilidade de determinar e incluir este composto na simulação é provavelmente da mesma ordem de grandeza dos erros devidos as outras determinações experimentais.

A partir dessas duas estimativas, apresentadas nas Figuras 4 e 5 , resulta evidente que a determinação da concentração total e da composição da mistura de COVs é fundamental para a obtenção de resultados representativos, especialmente para relações $\mathrm{COVs} / \mathrm{NO}_{x}$ baixas, que, como será explicado, tornam o sistema químico controlado por COVs (concentração total e especiação).

Quanto à altura da camada de mistura e os valores de emissões, deve considerar-se esses números apenas como parâmetros de ajuste, sem ser possível extrair outra informação mais relevante a partir deles.

Este tipo de modelo é particularmente útil para discutir os aspectos químicos relacionados às concentrações de ozônio, em particular o efeito das relações $\mathrm{COV} / \mathrm{NO}_{\mathrm{x}}$ e da especiação.

Para exemplificar, foram utilizadas as condições do caso base 1 para calcular as concentrações máximas de ozônio para diferentes valores de concentrações de $\mathrm{NO}_{\mathrm{x}}$ e COVs. Os valores obtidos são representados na forma de curvas de igual concentração, conhecidas como isopletas de ozônio, mostradas na Figura 6. Tais curvas mostram claramente a dependência não linear das concentrações de ozônio com as variações nas concentrações de COVs e $\mathrm{NO}_{\mathrm{x}}$.

Relações COVs/ $\mathrm{NO}_{x}$ baixas (tipicamente 6 ou menores) são achadas, em geral, em ambientes urbanos muito poluídos, por exemplo na área central da cidade. Nessas condições a diminuição nas concentrações de COVs $\left(\right.$ a $\mathrm{NO}_{x}$ constante) é efetiva na diminuição das concentrações de $\mathrm{O}_{3}$, enquanto a diminuição das concentrações de $\mathrm{NO}_{\mathrm{x}}$ (a COVs constante) leva a um aumento das concentrações máximas de $\mathrm{O}_{3}$. Nessas condições o sistema é controlado pelas concentrações (e especiação) de COVs. Esse comportamento complexo é devido a vários efeitos: em primeiro lugar a reação de $\mathrm{O}_{3}$ com $\mathrm{NO}$ é rápida, levando ao consumo direto do ozônio. Além disso, nessas condições, o $\mathrm{NO}_{2}$ reage com os radicais hidroxila, formando $\mathrm{HNO}_{3}$, terminando a cadeia de reações que levam à transformação de NO para $\mathrm{NO}_{2}$ (e consequente formação de $\mathrm{O}_{3}$ ) e diminuindo a formação de radicais $\mathrm{HO}_{2}$, através da reação dos $\mathrm{COV}$ s com radicais hidroxila. ${ }^{2}$

Em altas relações $\mathrm{COV} / \mathrm{NO}_{\mathrm{x}}$ (tipicamente 12 a 15), a diminuição nas concentrações de COVs leva a uma discreta diminuição nas concentrações de $\mathrm{O}_{3}$, enquanto a diminuição de $\mathrm{NO}_{\mathrm{x}}$ é efetiva no controle das concentrações de $\mathrm{O}_{3}$. Nesse caso, o sistema e controlado pelas concentrações de $\mathrm{NO}_{\mathrm{x}}$ e corresponde, geralmente, a áreas de subúrbio, rurais ou downwind.

Neste trabalho, a relação COVs/ $/ \mathrm{NO}_{x}$ para o caso base 1 no início da simulação é de 8,9. Tal valor sugere, como pode ser observado nas isopletas (Figura 6), uma dependência, ainda que não equivalente, das emissões de $\mathrm{NO}_{\mathrm{x}}$ e COVs para a formação de ozônio.

Nesse caso e nessas condições, uma diminuição nas concentrações de COVs acarretará em um decréscimo na formação de ozônio, enquanto que uma diminuição nas concentrações de $\mathrm{NO}_{\mathrm{x}}$ ocasionaria um aumento nos níveis deste poluente secundário.

Já a sensibilidade à especiação pode ser mostrada usando a distribuição de COVs determinada na campanha 02 para simular as concentrações de ozônio com o modelo ajustado para o caso 1 (condições meteorológicas, emissões e concentrações iniciais). Nesse caso, a concentração máxima calculada é de 9,57 ppbv às 14:08 h. Esse resultado sugere que a mistura de COVs na segunda campanha tem um potencial de formar ozônio muito menor. $\mathrm{O}$ fato das concentrações de ozônio calculadas para o caso base 2 serem aproximadamente iguais às do caso base 1 se deve ao fato de que a concentração inicial total de COVs foi 2,3 vezes maior que a do caso base 1 , enquanto as concentrações de $\mathrm{NO}_{\mathrm{x}}$ iniciais foram semelhantes (diferença de aproximadamente 15\%), levando, consequentemente, à uma maior formação de $\mathrm{O}_{3}$. Isso mostra que o caso base deve ser ajustado para cada condição particular e que a especiação de COVs é um dado crítico para a simulação.

A necessidade de determinar as concentrações de $\mathrm{NO}_{x}$ e COVs, a relação COVs $/ \mathrm{NO}_{x}$ e a especiação de COVs para realizar uma simulação confiável e representativa limita o uso do modelo a situações nas quais se dispõe, como mínimo, de dados de concentração dos poluentes legislados medidos por uma estação de monitoramento e de dados sobre a concentração e especiação de COVs medidos usando um método ou um conjunto de métodos que permitam determinar os compostos carbonílicos e os hidrocarbonetos mais reativos.

A comparação com dados de simulação obtidos com um modelo 3D não é possível para o Rio de Janeiro porque não se dispõe de

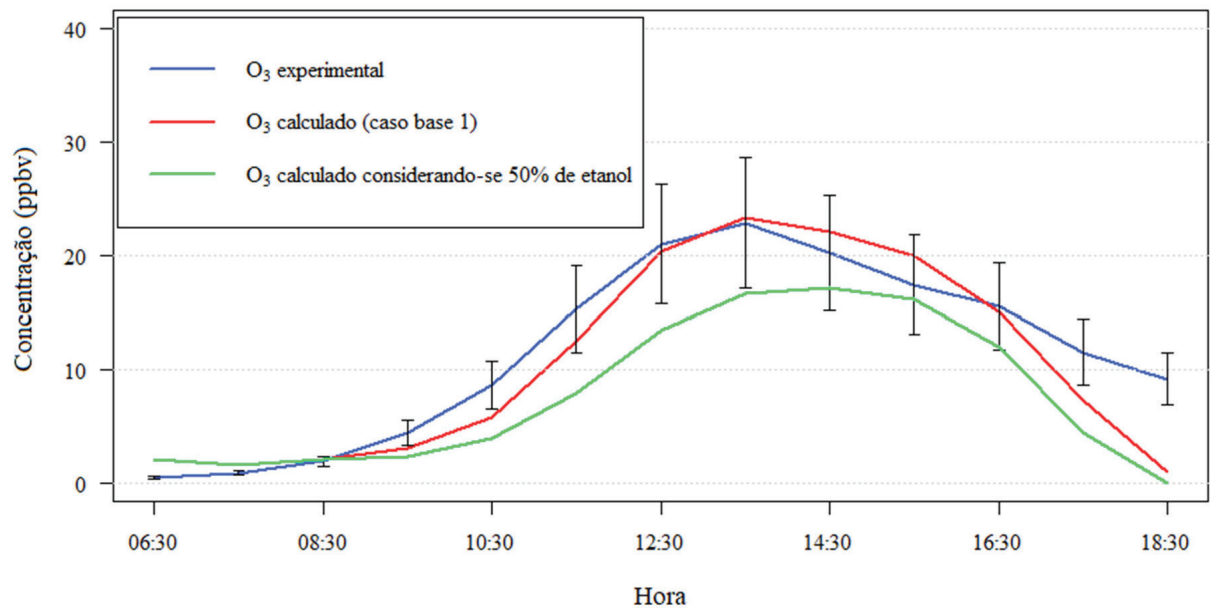

Figura 5. Valores de concentração simulados e experimentais para o $\mathrm{O}_{3}$, considerando o caso base 1 e simulação utilizando $50 \%$ de etanol da massa total de COVs. Concentrações em unidades de ppbv 


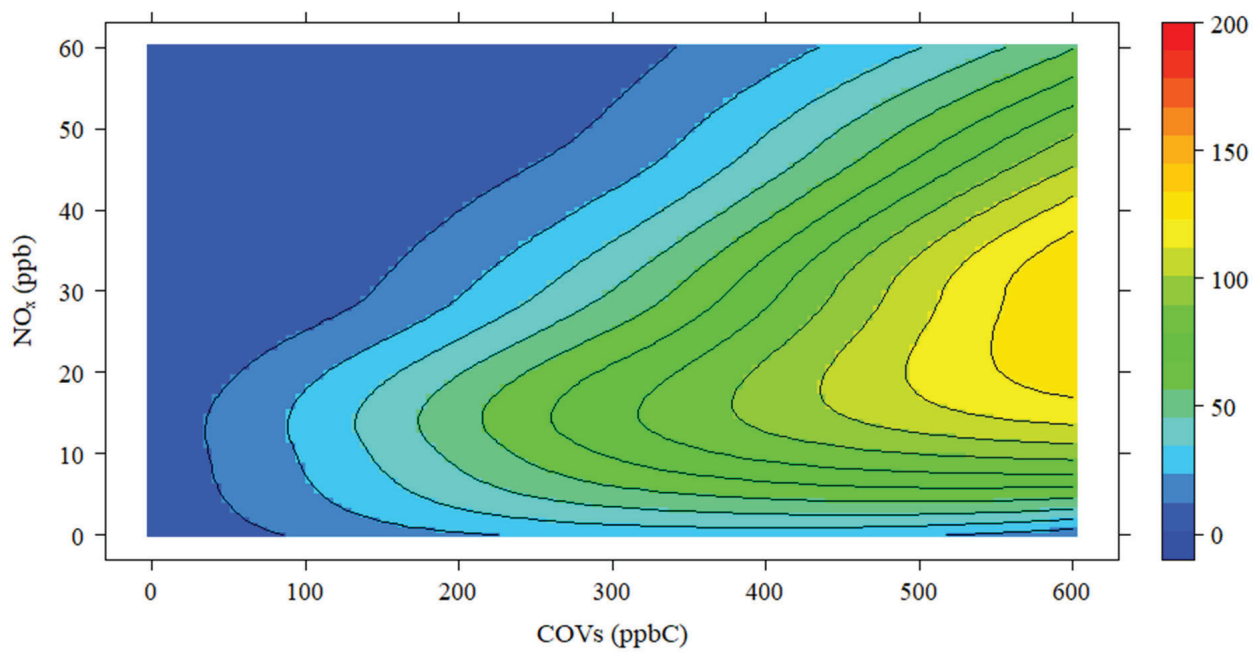

Figura 6. Isopletas de $\mathrm{O}_{3}$ calculadas para as condições do caso base 1 (campanha 01, mês de março de 2015)

dados suficientes das estações de monitoramento, já que a maioria delas medem apenas alguns poluentes, faltando principalmente dados fundamentais como as concentrações de $\mathrm{NO}_{x}$. No período estudado apenas quatro estações de monitoramento na cidade do Rio de Janeiro obtinham e disponibilizavam dados meteorológicos e de qualidade do ar completos, o que é muito deficiente para a implementação de um modelo 3D. Para um estudo dessa magnitude, seria necessária a instalação de outras estações de monitoramento, formando uma rede em toda a região metropolitana. Porém, deve ser mencionado que esse modelo, mesmo que relativamente simples em comparação com modelos $3 \mathrm{D}$, permite o entendimento de diversos processos cinéticos na atmosfera e tem sido usado em estudo de reatividade, ${ }^{43,49,51}$ determinação de conjunto mínimo de COVs representativos, ${ }^{6}$ estudo de episódios de poluição ${ }^{36,39}$ e elaboração de estratégias de controle da qualidade do ar..$^{54}$

\section{CONCLUSÕES}

Neste trabalho é apresentada uma modelagem das concentrações de ozônio realizada utilizando o modelo de qualidade do ar OZIPR e o mecanismo químico SAPRC. Esse modelo tem sido utilizado previamente pela comunidade internacional e por pesquisadores brasileiros para auxiliar na compreensão dos processos de formação de ozônio troposférico. A principal contribuição deste trabalho é apresentar em forma detalhada o conjunto mínimo de dados necessários, o tratamento típico dos mesmos, o procedimento de ajuste do caso base ou caso típico e discutir a confiabilidade dos resultados obtidos. De uma forma geral, os trabalhos publicados na literatura têm utilizado o modelo para obter valiosas informações sobre reatividade e o processo de formação de ozônio, mas na maioria dos estudos não é demonstrada a sensibilidade dos resultados aos parâmetros de entrada. Assim, este trabalho pode contribuir para um melhor conhecimento deste tipo de modelo e no futuro divulgar seu uso especialmente entre a comunidade da química ambiental no Brasil. O modelo requer poucos recursos computacionais e um número limitado de dados experimentais, que é a condição geralmente encontrada em muitas cidades brasileiras. Os resultados mostram que, mesmo com um conjunto limitado de dados, é possível obter conclusões importantes com respeito ao processo de formação de ozônio, especialmente para determinar a reatividade dos COVs e a dependência das concentrações obtidas com a relação $\mathrm{NO}_{x}{ }^{\prime}$ COVs. Esses resultados podem auxiliar na tomada de medidas para a melhoria da qualidade do ar, por exemplo a redução da frota veicular (que afetará as concentrações totais) e mudanças na composição da frota (que afetam as relações $\mathrm{NO}_{x} / \mathrm{COV}$ s e a distribuição de COVs).

\section{MATERIAL SUPLEMENTAR}

Figuras e Tabelas utilizadas neste trabalho estão disponíveis em http://quimicanova.sbq.org.br, na forma de arquivo PDF, com acesso livre. Figura 1S (Local de estudo); Figura 2S (Boxplot com a concentrações determinadas na estação de monitoramento na primeira campanha); Figura 3S (Boxplot com a concentrações determinadas na estação de monitoramento na segunda campanha); Figura 4S (Boxplot com os valores de temperatura e umidade determinados na estação de monitoramento na primeira campanha); Figura 5S (Boxplot com os valores de temperatura e umidade determinados na estação de monitoramento na segunda campanha); Figura 6S (Rosas dos ventos para a primeira campanha); Figura 7S ( Rosas dos ventos para a segunda campanha); Figura 8S (Boxplot com a radiação); Figura 9S (Perfil da temperatura e a altura da camada de mistura para o mês de março de 2015), Figura 10S (Valores de concentração simulados e valores de mediana experimentais para o CO para o caso base 1); Figura 11S (Valores de concentração simulados e experimentais para o $\mathrm{NO}_{\mathrm{x}}$, para caso base 1); Figura 12S (Valores de concentração simulados e valores de mediana experimentais para o CO para o caso base 2); Figura 13S (Valores de concentração simulados e experimentais para o $\mathrm{NO}_{x}$ para o caso base 2); Tabela $1 \mathrm{~S}$ (Agrupamento dos COVs utilizado no modelo químico SAPRC); Tabela $2 \mathrm{~S}$ (Especiação de COVs para o caso base 1); Tabela 3S (Relações das emissões para diferentes horários, utilizadas no caso base 1); Tabela 4S (Especiação de COVs para o caso base 2).

\section{AGRADECIMENTOS}

Os autores agradecem o apoio financeiro da Fundação de Amparo a Pesquisa do Rio de Janeiro (FAPERJ), a Coordenação de Aperfeiçoamento de Pessoal de Nível Superior (CAPES), o Conselho Nacional de Desenvolvimento Científico e Tecnológico (CNPq) e o Centro de Pesquisas Leopoldo Américo Miguez de Mello/Petrobras. Agradecem especialmente à Secretaria Municipal de Meio Ambiente (SMAC) pela colaboração constante e por ceder os dados da estação de monitoramento para este trabalho. Agradecem, também, valiosas sugestões dos revisores.

\section{REFERÊNCIAS}

1. Environmental Simulation Chambers: Application to Atmospheric Chemical Processes; Barnes, I., Rudzinski, K., eds.; NATO Science Series, Springer: Netherlands, 2006. 
2. Finlayson-Pitts, B. J.; Pitts, J. N.; Chemistry of the Upper and Lower Atmosphere. Theory, Experiments and Applications, $3^{\text {rd }}$ ed. Academic Press: San Diego, 2000.

3. Gulia, S.; Shiva Nagendra, S. M.; Khare, M.; Khanna, I.; Atmos. Pollut. Res. 2015, 6, 286.

4. Guarieiro, L. L. N; Amparo, K. K. S.; Figueiredo, I. S.; de Andrade, J. B.; Rev. Virtual Quim. 2017, 9, 2082.

5. Brasseur, G. P.; Jacob, D. J.; Modeling of Atmospheric Chemistry, $1^{\text {st }}$ ed., Cambridge University Press: Cambridge, 2017.

6. Silva, C. M.; da Silva, L. L.; Corrêa, S. M.; Arbilla, G.; Atmos. Pollut. Res. 2018, 9, 369.

7. Carter, W. P. L.; Atmos. Environ. 1990, 24A, 481.

8. Gery, M. W.; Whitten, G. Z.; Killus, J. P.; J. Geophys. Res. 1989, 20, 925.

9. Faraji, M.; Kimura, Y.; McDonald-Buller, E.; Alle, D.; Atmos. Environ. 2008, 42, 5821.

10. Luecken, D. J.; Phillips, S.; Sarwar, G.; Jang, C.; Atmos. Environ. 2008, 42, 5805 .

11. Thunis, P.; Miranda, A.; Baldasano, J. M.; Blond, N.; Douros, J.; Graff, A.; Janssen, S.; Juda-Rezler, K.; Karvosenoja, N.; Maffeis, G.; Martilli, A.; Rasoloharimahefa, M.; Real, E.; Viaene, P.; Volta, M.; White, L.; Environ. Sci. Policy 2016, 65, 13.

12. https://cidades.ibge.gov.br/brasil/rj/rio-de-janeiro/panorama, acessada em janeiro 2010.

13. http://www.rio.rj.gov.br/dlstatic/10112/3252594/4114836/ RelatorioMonitorar20112012.pdf, acessada em janeiro 2019.

14. https://inside.fei.org/system/files/RIO\%20Weather\%20forecast_0.pdf, acessada em janeiro 2019.

15. http://www.parquedatijuca.com.br/quemsomos.php\#parque, acessada em janeiro 2019.

16. Silva, C. M.; da Silva, L. L.; Corrêa, S. M.; Arbilla, G.; Rev. Virtual Quim. 2017, 9, 1887.

17. https://www3.epa.gov/ttnamti1/files/ambient/airtox/to-15r.pdf, acessada em janeiro 2019.

18. Silva, C. M.; Souza, E. C. C. A.; da Silva, L. L.; Oliveira, R. L.; Arbilla, G.; Corrêa, S. M.; Quim. Nova 2016, 39, 1245.

19. https://www3.epa.gov/ttnamti1/files/ambient/airtox/to-11ar.pdf, acessada em janeiro 2019.

20. Corrêa, S. M.; Arbilla, G.; Martins, E. M.; Quitério, S. L.; Guimarães, C. S.; Gatti, L. V.; Atmos. Environ. 2010, 44, 2302.

21. http://www.rio.rj.gov.br/web/smac/monitorar-rio1, acessada em janeiro 2019.

22. Tsuruta, F.; Carvalho, N. J.; Silva, C. M.; Arbilla, G.; J. Braz. Chem. Soc. 2018, 29, 1291

23. http://jeap.rio.rj.gov.br/je-metinfosmac/institucional/docs/entenda_iqa. pdf, acessada em janeiro 2019.

24. http://jeap.rio.rj.gov.br/je-metinfosmac/boletim, acessada em janeiro 2019.

25. https://www.r-project.org/, acessada em janeiro 2019.

26. http://www.openair-project.org/, acessada em janeiro 2019.

27. https://www3.epa.gov/scram001/userg/other/ozipr.pdf, acessada em janeiro 2019.

28. Tonnessen, G. S.; Users's Guide for Executing OZIPR, Version 2.0, US EPA: North Caroline, 2000.
29. Air Pollution Modelling and Application XIV, Gryning, A. E., Schiermeier, F. A., eds.; Kluwer Academic Publishers: New York, 2004.

30. Silva, C. M.; Corrêa, S. M.; Arbilla, G.; Bull. Environ. Contam. Toxicol. 2018, 100, 184

31. Jacob, D. J.; Introduction to Atmospheric Chemistry, Princeton University Press: Princeton, 1999.

32. Seinfeld, J. H.; Pandis, S. N.; Atmospheric Chemistry and Physics: From Air Pollution to Climate Change, $3^{\text {rd }}$ ed., John Willey \& Sons: Hoboken, 2016.

33. Carter, W. P. L.; Atmos. Environ. 2010, 44, 5324.

34. http://www.engr.ucr.edu/ carter/SAPRC/, acessada em janeiro 2019.

35. http://www.engr.ucr.edu/ carter/SAPRC/saprc07, acessada em janeiro 2019.

36. Martins, E. M.; Nunes, A. C.; Corrêa, S. M.; J. Braz. Chem. Soc. 2015, 26, 1967

37. http://alertario.rio.rj.gov.br/, acessada em dezembro 2017.

38. Miller, J. N.; Miller, J. C. Statistics and Chemometrics for Analytical Chemistry, $5^{\text {th }}$ ed.; Pearson/Prentice Hall: Upper Saddle River, 2005.

39. Geraldino, C. G. P.; Martins, E. M.; Silva, C. M.; Arbilla, G.; Bull. Environ. Contam. Toxicol. 2016, 98, 632.

40. http://www.mma.gov.br/port/conama/res/res90/res0390.html., acessada em janeiro 2019

41. http://www.inmet.gov.br/portal/index.php?r=clima/ normaisclimatologicas, acessada em janeiro 2019.

42. Martins, E. M.; Arbilla, G.; Atmos. Environ. 2003, 37, 1715.

43. Orlando, J. P.; Dissertação de Mestrado, Universidade de São Paulo, Brasil, 2008.

44. http://www.masterantiga.iag.usp.br/ind.php?inic=00\&prod=sondagem, acessada em janeiro 2019.

45. http://cetesb.sp.gov.br/veicular/, acessada em janeiro 2019.

46. http://cetesb.sp.gov.br/veicular/wp-content/uploads/sites/6/2013/12/ Relatorio-Emissoes-Veiculares-2015-v4_.pdf, acessada em janeiro 2019.

47. http://www.mma.gov.br/estruturas/163/_arquivos/inventario_ veicular2010_163.pdf, acessado em janeiro 2019.

48.www.inea.rj.gov.br/cs/groups/public/@inter_vpres_geiat/documents/ document/zwew/mti3/ edisp/inea0127611.pdf, acessado em janeiro 2019.

49. Alvim, D. S.; Tese de Doutorado, Universidade de São Paulo, Brasil, 2013.

50. Colon, M.; Pleil, J. D.; Hartlage, T. A.; Guardani, M. L.; Martins, M. H.; Atmos. Environ. 2001, 35, 4017.

51. Alvim, D. S.; Gatti, L. V.; Corrêa, S. M.; Chiquetto, J. B.; Santos, G. M.; Rossatti, C. de S.; Pretto, A.; Rozante, J. R.; Figueroa, S. N.; Pendharkar, P. N.; Aerosol Air Qual. Res. 2018, 18, 2460.

52. Dominutti, P. A.; Nogueira, T.; Borbon, A.; Andrade, M. de F.; Fornaro, A.; Atmos. Environ. 2016, 142, 371.

53. Alvim, D. S.; Gatti, L. V.; Corrêa, S. M.; Chiquetto, J. B.; Rossatti, C. de S.; Pretto, A.; Santos, M. H. de; Yamazaki, A.; Orlando, J. P.; Santos, G.; Air Qual., Atmos. Health 2017, 10, 421.

54. Lan, J.; Sun-Hwa, L.; Hye-Jung, K.; Yong-Pyo, K.; Asian J. Atmos. Chem. 2012, 6, 111. 